\title{
Characterization of Black Carbon Collected from Candle Light and Automobile Exhaust Pipe
}

\author{
Seo-Rin Cho and Han-Gook Cho ${ }^{\dagger, *}$ \\ Bakmun Girl's High School, 1 Bakmun-ro, Dong-gu, Incheon 401-818, South Korea \\ ${ }^{\dagger}$ Department of chemistry, Incheon National University, 12-1 Songdo-dong, Yeonsu-gu, Incheon 406-840, South Korea. \\ *E-mail: hgc@incheon.ac.kr
}

(Received October 23, 2013; Accepted November 5, 2013)

\begin{abstract}
Black carbon contributes to global warming and melting of polar ice as well as causing respiratory diseases. However, it is also an inexpensive, easily available carbon nano material for elementary chemistry experiments. In this study, black carbon samples collected from candle light and automobile exhaust pipes have been investigated to examine their compositions and surface characteristics. The observed broad G and D bands and amorphous $\mathrm{sp}^{3}$ band in their Raman spectra as well as the high intensity of the D (defect) band reveal that black carbon is principally made of amorphous graphite. The black carbon deposits in automobile exhaust pipes are apparently more amorphous, probably due to the shorter time allowed for formation of the carbonaceous matter. An exceptionally large water contact angle $\left(159.7^{\circ}\right)$ is observed on black carbon, confirming its superhydrophobicity. The surface roughness evidently plays an important role for the contact angle much larger than that of crystalline graphite $\left(98.3^{\circ}\right)$. According to the Sassie-Baxter equation, less than $1 \%$ the area actually in contact with the water drop.
\end{abstract}

Key words: Black carbon, Raman, Contact angle, Graphite, Hydrophobicity

\section{INTRODUCTION}

Black carbon casts a dark shadow worldwide from congested megacities to the arctic ice that sustains polar bears and other wildlife. ${ }^{1}$ The environmental effects of black carbon have recently drawn much attention. Greenhouse gases are the chief culprit in global warming, but latest studies show that these microscopic airborne particles commonly known as 'soot' are also a big factor, accounting for as much as half of arctic warming by directly absorbing sunlight. Its air pollution is also a leading cause of respiratory illness and death.

This polluting substance is produced in combustion of carbon-containing materials. Hydrogen burns easily, but carbon normally does not have enough time to mix with air, the unburned carbon coalescing to form the black matter. Black carbon is also one of the earliest known materials to humans. Previous reports show that black carbon consists of carbonaceous particles ranging 5-50 nm usually in spherical shape or branched aggregates containing thousands of these particles. ${ }^{1}$ They reportedly contain irregular graphite (or graphene) fragments as well as minor components such as carcinogenic polycyclic aromatic hydrocarbons (PAH's), fullerene or nanotube arrays, various oxides, etc.

This nano material easily accessible in our daily life provides good opportunities for students to investigate its chemical composition and properties. In this study, we have carried out spectroscopic study of the black carbon samples gathered from candle light and automobile's tail pipes. Raman spectroscopy has turned out to be a very effective tool to characterize black carbon. We also measured the contact angle of water drop resting on black carbon to investigate its surface properties and succeeded in observation of its superhydrophobicity.

\section{EXPERIMENTAL}

\section{Raman, Infrared, and UV-vis Spectrometers}

Raman spectroscopy is known to be well suited to detect small changes in structural morphology of carbon nanostructures. The Raman spectrometer used in this study is a home-built Raman setup with an inverted microscope (Olympus IX71), whose details had been reported previously elsewhere. ${ }^{2}$ Briefly, the laser beam of a He-Ne or a diode (532 or $491 \mathrm{~nm}$ ) laser is filtered by a narrow bandpass filter and its power adjusted to $\sim 8 \mathrm{~mW}$. It is directed to a $40 \mathrm{x}$ objective, and the back scattered Raman signal is collected and directed into a spectrograph (Acton Research, Spectra Pro 2500) equipped with a TE-cooled, back-illuminated CCD detector (Princeton Instrument, PIXIS: 100B). The spectrometer was run at $4.0 \mathrm{~cm}^{-1}$ resolution based on 
the extent of isotope splitting of $\mathrm{CHCl}_{3}$ spectrum. ${ }^{3}$

The IR spectra were recorded at a resolution of $1.0 \mathrm{~cm}^{-1}$ with Varian 640-IR. The sample was dispersed in KBr. KMAC SV 2100 was used to take the UV-vis spectrum. Black carbon is mixed with mineral oil and applied to the inner surface of a quartz cuvette (Aldrich Z27690, 10×10×4.5 $\mathrm{mm}$ ) to observe its UV-vis spectrum.

\section{Contact Angle Goniometer}

A home-built contact angle goniometer was used. Its details have been described elsewhere. ${ }^{4}$ Briefly, a bike LED lantern (HL-AU230) is used as the light source, an inclinable stage (Thorlab GN05, $\pm 15^{\circ}$ inclinable) as the sample stand, and a digital TTL camera (Nikon D600) equipped with a close-up lenz (Nikon AF Micro Nikkor $105 \mathrm{~mm} \mathrm{f/2.8D)}$ as the image recorder. These components are fixed on an optical bread board (Thorlab MB4560M, $60 \times 45 \mathrm{~cm}$ ). The sample area is covered with a box $(25 \times 16 \times 18.5 \mathrm{~cm})$ with holes $(6.6 \mathrm{~mm})$ on both sides to block extra light from outside, and the one on the LED light source side is covered with tracing paper working as a diffuser.

Focusing and exposure setting were done manually to prevent automatic focusing on a higher contrast objects such as the glass slide or sample stand surface and automatic exposure adjustment by camera. Back illumination was used to observe the liquid drop as a dark image at the center of the bright background. In our experimental setup, the distance between the sample and camera image sensor was $35 \mathrm{~cm}$, the aperture size $\mathrm{f} / 16$, and the shutter speed $1 / 800 \mathrm{sec}$. At this aperture size, the depth of field is estimated to be $\sim 0.5 \mathrm{~cm}$, which is normally large enough to get a sharp image of a liquid drop without extra adjustment. A micro pipette (Eppendorf $20 \mu \mathrm{L}$ ) was used to form a $10 \mu \mathrm{L}$ liquid drop on black carbon surface.

The image of liquid drop was converted into a black-andwhite image using graphic software (Photoshop CS) and later analyzed with an open-source software, ImageJ with a JAVA plugin (Drop_analysis). The drop_snake method included in the Drop_analysis plugin was used in this investigation. ${ }^{4}$

\section{Chemicals and Samples}

Doubly distilled, deionized water and diiodomethane (Aldrich) were used for contact angle measurement. Glass slide (Marienfeld 76×26×1 mm) was used to collect black carbon from candle light. The slide was later placed over the objective lens of the microscope for observation of the Raman spectrum. Other black carbon samples were collected from automobile exhaust pipes and inserted in capillary for Raman observation. The candle used in this study
(E-Mart Loving Home plane candle) was bought at a supermarket. Graphite flake (Aldrich) and carbon electrode (Staedtler Mars carbon) were used as references for the carbonaceous material (black carbon).

\section{RESULTS AND DISCUSSION}

\section{Raman Spectra}

Shown in Fig. 1 are the Raman spectra of black carbon from candle light, carbon electrode, and graphite flake. The sharp, strong $\mathrm{G}$ ( $\mathrm{G}$ for Graphite), strong $\mathrm{G}^{\prime}$ and weak $\mathrm{D}$ bands from the graphite flake all indicate its high crystallinity. ${ }^{5}$ The $\mathrm{G}^{\prime}$ band is also called as $2 \mathrm{D}$ band. On the contrary, the corresponding $\mathrm{G}$ and $\mathrm{D}$ bands in the black carbon spectrum are much broader, due to its low crystallinity (amorphousness). These primary graphite G, D, and $\mathrm{G}^{\prime}$ bands appear in our spectra at 1584, 1340, and $2686 \mathrm{~cm}^{-1}$. Previous studies show that the D band is weak in the spectrum of crystalline graphite and its relative intensity increases with amorphousness (D stands for Defect). ${ }^{5}$ The $\mathrm{G}$ band (also known as tangential band) is due to the bond stretch-

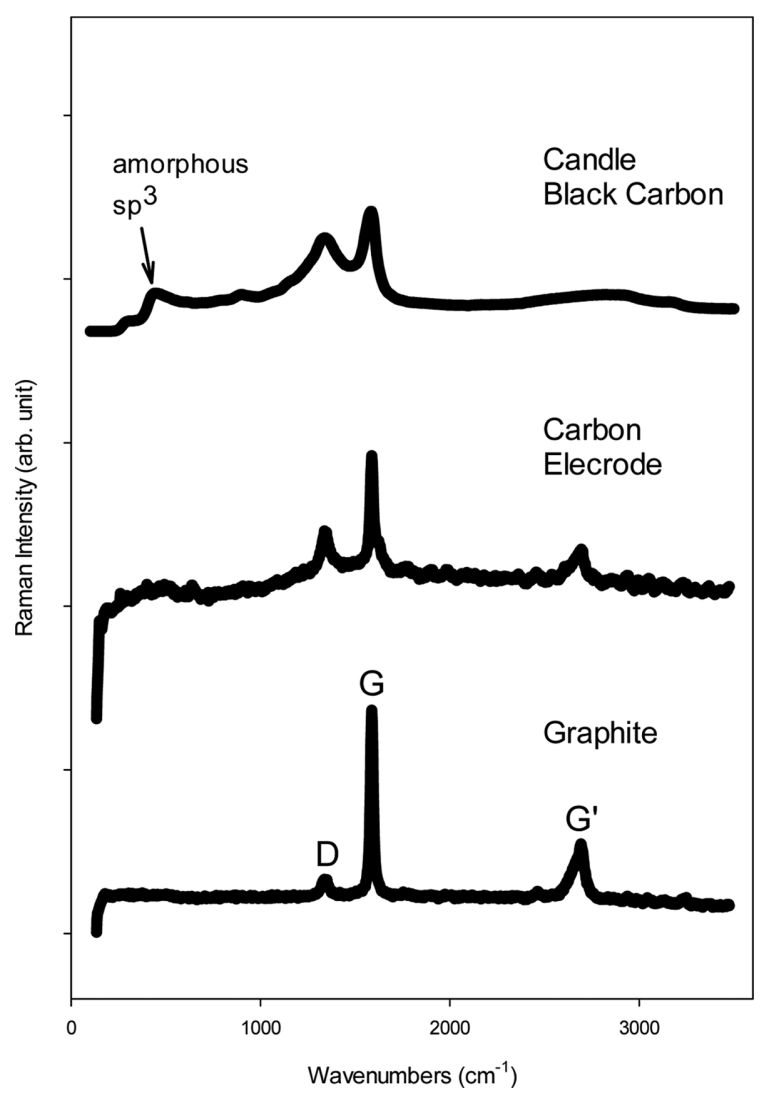

Figure 1. Raman spectra of graphite, carbon electrode, and black carbon from candle light. Notice the evolution of the G and D bands and appearance of the amorphous $\mathrm{sp}^{3}$ carbon band in the candle black carbon spectrum. The $491 \mathrm{~nm}$ diode laser is used. 


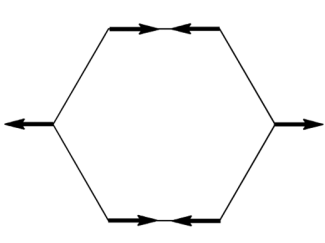

$E_{2 g}$

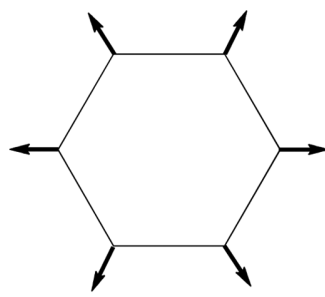

$A_{1}^{\prime}$
Figure 2. Graphite $E_{2 g}$ and $A_{1}{ }^{\prime}$ vibrational modes. The $\mathrm{G}$ and $\mathrm{D}$ bands arise from the $E_{2 g}$ and $A_{1}^{\prime}$ vibrational modes of the sixmembered rings of the two-dimensional graphite (graphene) plane.

ing of all pairs of carbon $\mathrm{sp}^{2}$ atoms ( $E_{2} g$ in Fig. 2). The D peak originates from the breathing $\left(A_{1}^{\prime}\right)$ modes of $\mathrm{sp}^{2}$ atoms in rings, whereas the $\mathrm{G}^{\prime}$ band is the overtone (double the frequency) of the $\mathrm{D}$ band (2D).

The $\mathrm{G}$ and $\mathrm{D}$ bands observed in the black carbon Raman spectrum shown in Fig. 1 substantiate that graphite is the primary component of the carbonaceous material. Nano diamond and C60 would show strong bands at 1620 and $1462 \mathrm{~cm}^{-1}$, respectively, while the $\mathrm{G}^{\prime}$ band would be stronger than the $\mathrm{G}$ band in the graphene spectrum. Carbon nano tubes would show radial breathing mode (RBM) bands in the low frequency region below $400 \mathrm{~cm}^{-1}$. These characteristic Raman bands of the best known carbon materials other than graphite are not observed in this study due to their low concentrations.

The bands much broader than those in the graphite flake spectrum reflect its inhomogeneous microscopic environment, which leads to a distribution of vibrational transition energies. Moreover, the $\mathrm{D}$ band is considerably stronger than those in the graphite and carbon electrode spectra, another evidence for the low crystallinity. The last piece of information for the microscopic structure in black carbon is the amorphous $\mathrm{sp}^{3}$ band at $\sim 500 \mathrm{~cm}^{-1}$, revealing that unlike graphite consisted of all $\mathrm{sp}^{2}$ carbon, black carbon contains a substantial amount of $\mathrm{sp}^{3}$ carbon forming nonplanar structure. Consequently the black carbon from candle light is primarily inhomogeneous, amorphous graphite.

Fig. 3 shows the Raman spectra of the black carbon samples collected from automobile exhaust pipes, also showing the distinctive broad $\mathrm{G}$ and $\mathrm{D}$ bands. Clearly, these black carbon samples are also largely amorphous graphite. Substantially larger amounts of black carbon deposit were observed from Diesel engine automobiles (e.g., Audi A6 and Kia Carnival). The higher carbon content of the Diesel fuel (distilled at $200-350{ }^{\circ} \mathrm{C}, \mathrm{C}_{10}-\mathrm{C}_{15}$ ) makes it more prone to be incompletely oxidized than the gasoline

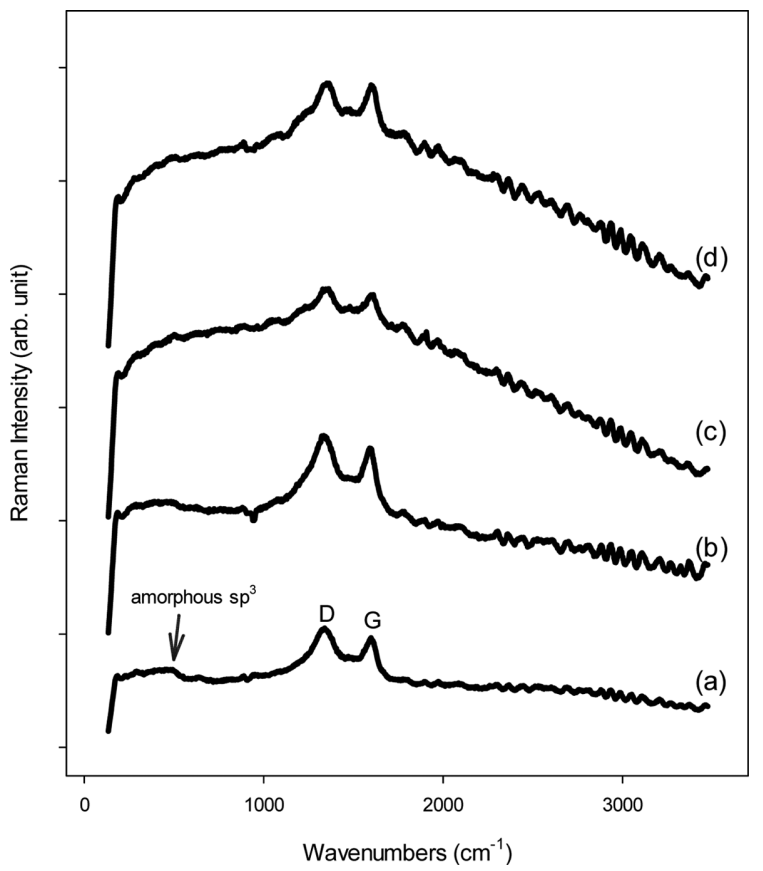

Figure 3. Raman spectra of black carbon sampled from automobile exhaust pipes. (a) Kia Carnival (Diesel), (b) Ssangyoung Musso (Diesel), (c) Kia Morning (gasoline), and (d) Audi A6 (Diesel). Notice that the Raman spectra are basically the same as that of the black carbon from candle light.

fuel (distilled at $30-200{ }^{\circ} \mathrm{C}, \mathrm{C}_{4}-\mathrm{C}_{12}$ ), generating more black carbon. In addition, the $\mathrm{D}$ bands in these Raman spectra are noticeably stronger than that of the candle light black carbon shown in Fig. 3, indicating lower crystallinities. Less time is probably allowed for production of black carbon during combustion of fuel in the internal combustion engine, reducing the crystallinity of the carbonaneous waste. The Raman spectra of the black carbon samples from other automobiles (e.g., Hyundai Veracruz (Diesel) and Avante (gasoline) and Kia Sportage (Diesel)) are all similar (not shown).

\section{Infrared and UV-visible Spectra}

The infrared and UV-vis spectra of candle light black carbon are shown in Fig. 4. The infrared and Raman methods are complementary one another. While symmetric stretching bands such as the $\mathrm{C}-\mathrm{C}$ stretching and ringbreathing bands are stronger in the Raman spectrum, the anti-symmetric stretching, polar bond stretching, and bending bands are more easily observed in the infrared spectrum. Particularly the $\mathrm{C}-\mathrm{H}$ and $\mathrm{C}-\mathrm{O}$ stretching bands are very strong in the infrared spectra, which reflect the presence of hydrocarbon and oxygen containing compounds, respectively. 

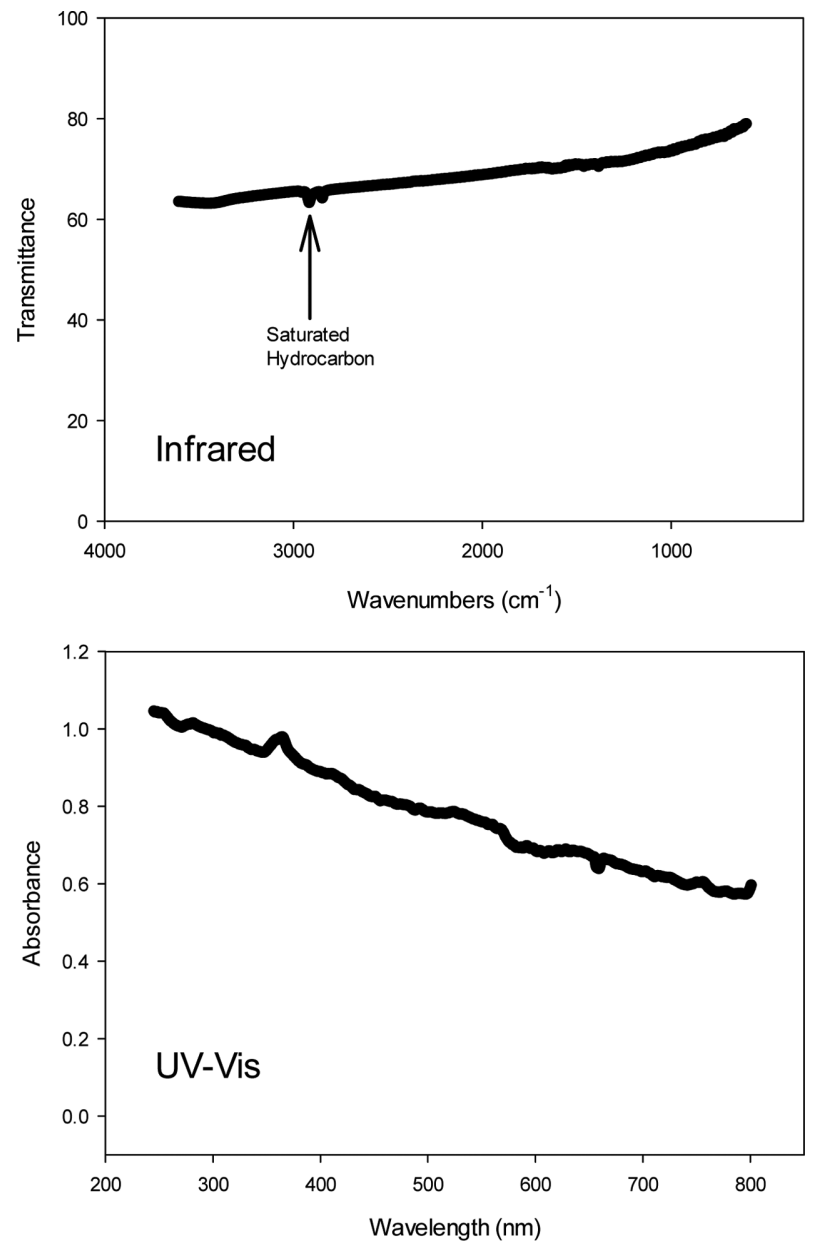

Figure 4. Infrared and UV-vis spectra of black carbon from candlelight. No particular IR band is observed other than the weak hydrocarbon absorptions at $\sim 2900 \mathrm{~cm}^{-1}$. Continuous absorption is observed in the visible and near UV region in UV-vis spectrum, leading to the black color.

The infrared spectrum shows no considerable bands except for the weak saturated hydrocarbon bands at $\sim 2900$ $\mathrm{cm}^{-1}$, showing that no detectable amounts of PAH's or oxides are included in the black carbon sample in this study. The $\mathrm{C}-\mathrm{H}$ and $\mathrm{C}-\mathrm{C}$ stretching bands of aromatic PAH's would appear at $\sim 3100$ and $\sim 1600 \mathrm{~cm}^{-1}$, whereas carbon oxides have $\mathrm{C}-\mathrm{O}$ and $\mathrm{C}=\mathrm{O}$ bonds, whose strong stretching bands would appear at $\sim 1100$ and $\sim 1700 \mathrm{~cm}^{-1}$. None of these bands are observed in this study.

The UV-vis spectrum shows virtually featureless broad absorption in the whole range of near-UV and visible region (240-800 nm), consistent with the typical graphite UV-vis absorption characteristics that lead to the black color. The small bumps in the UV-vis spectrum probably originate from minor non-graphite components. The long conjugated double bond system of graphite lowers the electron transition $\left(\pi \rightarrow \pi^{*}\right)$ energy well into the visible region.

Formation of black carbon during combustion has been studied in detail. ${ }^{5}$ Molecules dissociate in flame. While hydrogen diffuses fast and reacts with oxygen, heavier carbon is more difficult to mix with air and to burn. Atomic carbon instead quickly assembles aromatic hexagonal rings, and its planar structures grow in size via inception. Later they grow further by surface growth, coagulation, fragmentation, and even oxidation. As a result, the basic building material of black carbon is the aromatic rings. However, the crystallinity of black carbon is evidently very low due to numerous defects and vacancies along with the basic graphite structure. It is in fact loosely combined graphite bits with structural irregularities.

\section{Hydrophobicity}

Graphite is known to be a non-polar, hydrophobic material. One of the common methods to determine the hydrophobicity is to measure the contact angle of water drop sitting on solid surface. The balance between the interfacial forces shown in Fig. 5 determines the contact angle (Young equation (1)). ${ }^{6}$ The solid-gas surface energy $\left(\gamma_{S G}\right)$ is balanced with the sum of the solid-liquid surface energy $\left(\gamma_{S L}\right)$ and the horizontal component of the liquid-gas surface energy $\left(\gamma_{L G}\right), \gamma_{L G}$ is also called as "surface tension". $\gamma_{S L}$ becomes equal in size and opposite in direction to $\gamma_{S G}$ at a contact angle of $90^{\circ}$. This indicates that the liquid in fact behaves like the gas (no interaction) on the solid surface at the contact angle.

$$
\gamma_{S G}=\gamma_{S L}+\gamma_{L G} \cos \theta
$$

A contact angle smaller than $90^{\circ}$, therefore, reflects attractive interaction between the liquid and solid $\left(\left|\gamma_{S L}\right|<\right.$ $\left.\left|\gamma_{S G}\right|\right)$, hydrophilicity for water. When the contact angle equals $0^{\circ}, \gamma_{S L}$ vanishes and $\gamma_{L G}$ equals $\gamma_{S G}$ in size, and the liquid disperses on the solid surface, wettability. On the other hand, a contact angle larger than $90^{\circ}$ reveals that the solid surface repels the liquid $\left(\left|\gamma_{S L}\right|>\left|\gamma_{S G}\right|\right)$, hydrophobicity for water. A larger contact angle designates higher hydrophobicity. Particularly solid surfaces that yield a water

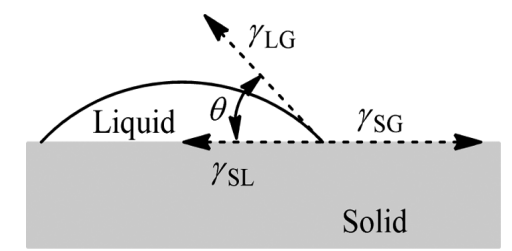

Figure 5. Balance of interfacial forces on liquid drop. $\gamma_{L G} \gamma_{S L}$, and $\gamma_{S G}$ stand for the liquid-gas, solid-liquid, and solid-gas interfacial energies. 
(a)

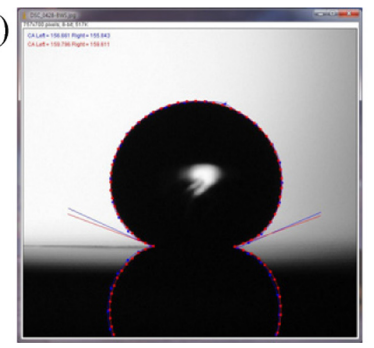

(b)

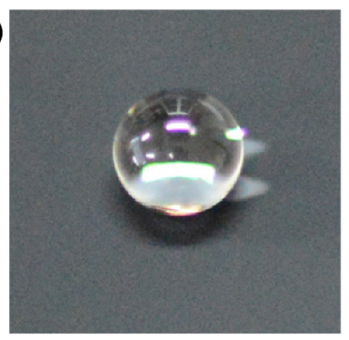

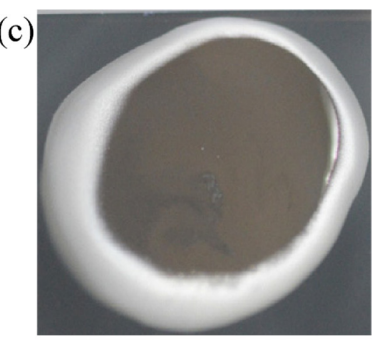

Figure 6. (a) Contact angle measurement of water droplet using Drop_analysis, (b) water droplet on black carbon, and (c) diiodomethane on black carbon. While black carbon shows superhydrophobicity, diiodomethane disperses on its surface due to dispersive (London) interaction. The surface roughness renders the hydrophobicity of graphite $\left(98.3^{\circ}\right)$ to the superhydrophobicity $\left(159.7^{\circ}\right)$.

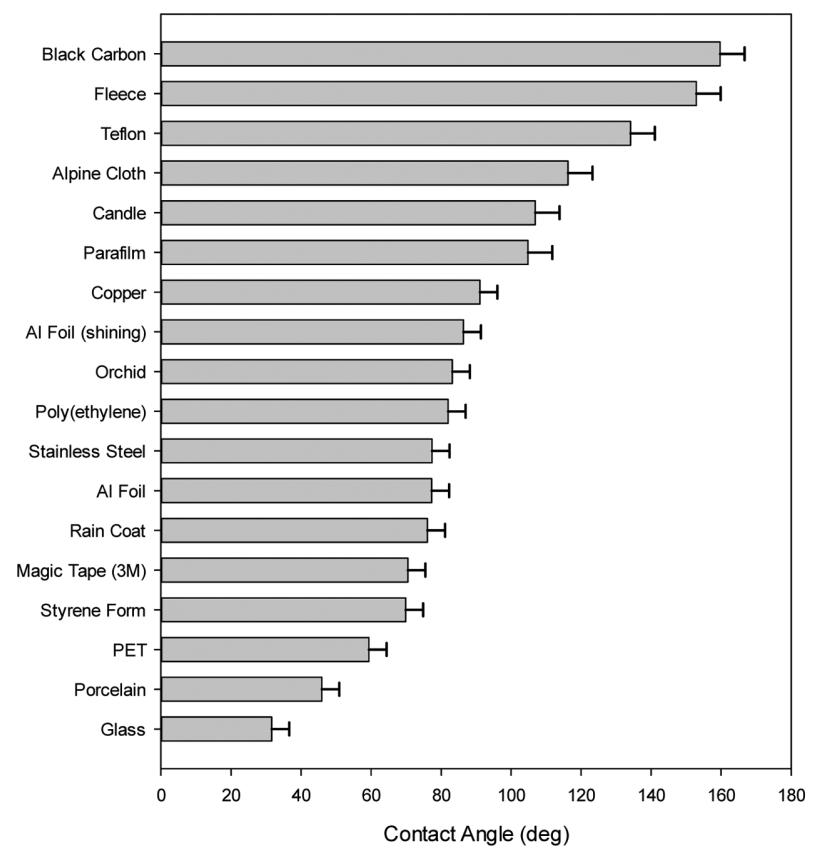

Figure 7. Contact angles of water droplet on various solid surfaces (Ref. 4). Notice that black carbon show superhydrophobicity with its highest contact angle $\left(159.7^{\circ}\right)$. It is believed that the water droplet on black carbon surface is in Cassie-Baxter state due to the surface roughness of the nano material.

contact angle larger than $150^{\circ}$ are called "superhydrophobic". Superhydrophobicity is of importance industrially as well as scientifically, due to the surface characteristics of water-repelling and self-cleaning. ${ }^{7}$

Fig. 6 shows water contact angle measurement on black carbon (a), a water drop formed on black carbon (b), and in contrast diiodomethane dispersed on the surface (c). The exceptionally large water contact angle on black carbon $\left(159.7^{\circ}\right)$ is surprising, which exceeds those of the wellknown water repelling materials such as paraffin, Teflon, and silicone. ${ }^{4}$ Fig. 7 shows the measured water contact angles on various materials using the same goniometer. ${ }^{4}$ It is also substantially larger than the previously reported water contact angle on graphite $\left(98.3^{\circ}\right) .{ }^{8}$ Therefore, it is
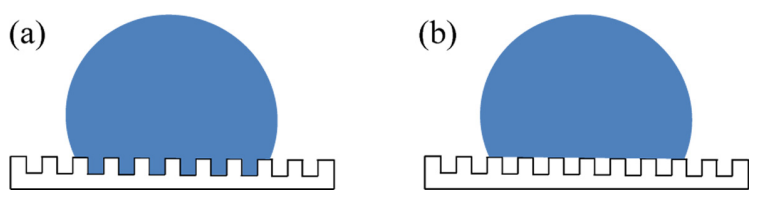

Figure 8. Wenzel (a) and Sassie-Baxter (b) states. The liquid is in contact with the entire solid surface under the drop regardless of the high or low points in the Wenzel state, while the liquid in contact with only the high points of the solid surface in the SassieBaxter state.

believed that the surface roughness plays an important role for the observed superhydrophobicity of black carbon.

Roughening a surface can enhance its hydrophobic behavior. Liquid contact on rough surface is normally understood in two different ways depending on its wetting ability. In the Wenzel state, the liquid is in contact with the entire surface under the liquid drop regardless of the high or low point of the surface as shown in Fig. $8 .^{7}$ The increased surface area caused by surface roughness in the Wenzel state makes hydrophobic surface more hydrophobic as represented in Eq. (2).

$$
\cos \theta_{\mathrm{W}, \text { rough }}=\left(A_{\text {actual,rough }} / A_{\text {projected,rough }}\right) \cdot \cos \theta_{\text {smooth }}
$$

where $\theta_{\mathrm{W}, \text { rough }}$ and $\theta_{\text {smooth }}$ are the contact angles measured on rough and smooth surfaces, and $A_{\text {actual,rough }}$ and $A_{\text {projected,rough }}$ the actual area of the rough surface and the projected area of that same rough surface.

The other type of liquid-to-solid contact is the CassieBaxter state, where the liquid is in contact only with the high points of the rough surface. ${ }^{7}$ The low regions are mostly occupied by air pocket. This contact is described by the parameter $\varphi$, the area fraction of the solid in direct contact with the liquid drop (Eq. (3)).

$$
\cos \theta_{\mathrm{CB}, \text { rough }}=\varphi\left(\cos \theta_{\text {smooth }}+1\right)-1
$$

where $\cos \theta_{\mathrm{CB} \text {,rough }}$ is the measured contact angle on rough surface in the Cassie-Baxter state, and $\varphi$ the area fraction of the solid in direct contact with the liquid drop. 
Black carbon deposits, which are consisted of carbonaceous nano particles, exhibit superhydrophobic behavior from Cassie-Baxter state of their rough hydrophobic substance. ${ }^{9} \varphi$ is determined to be 0.0724 from Eq. (3) and the known water contact angle on graphite $\left(98.3^{\circ}\right)$ and the measured value on black carbon $\left(159.7^{\circ}\right)$ with assuming that the black carbon is made of graphite. This indicates that less than $1 \%$ of the area is in contact with the water drop. While water is a typical polar liquid, diiodomethane $\left(\mathrm{CH}_{2} \mathrm{I}_{2}\right)$ is essentially a non-polar liquid, exhibiting strong dispersive intermolecular interaction. The $\mathrm{CH}_{2} \mathrm{I}_{2}$ contact angle is measured to be $3.3^{\circ}$. Due to its superhydrophobicity, dissolving black carbon in water is expected to be impossible without dispersing agent such as surfactant.

\section{CONCLUSION}

While black carbon is environmentally hazardous, it is also a naturally occurring, easily available nano material, which can be directly employed in high school or general chemistry experiments. Black carbon is primarily amorphous graphite on the basis of the characteristic G, D, and $\mathrm{G}^{\prime}$ bands without other considerable bands. The D (defect) band is significantly stronger than those observed from crystalline graphite, the $\mathrm{G}$ and $\mathrm{D}$ bands are markedly broader, and the amorphous $\mathrm{sp}^{3}$ band reflects the presence of nonplanar carbon structure. The black carbon samples collected from automobile exhaust pipes also show similar broad graphite $\mathrm{G}$ and $\mathrm{D}$ bands while the $\mathrm{D}$ band is even stronger, suggesting that they are even more amorphous probably because a shorter time is allowed for formation of the carbonaceous waste in the internal combustion engine.

The Infrared and UV-vis spectra of black carbon show no considerable absorption band other than the weak $\mathrm{C}-\mathrm{H}$ stretching band of saturated hydrocarbon. The PAH's and oxides are not detected in this study due to their low percentages. Superhydrophobicity of black carbon is confirmed by the measured water contact angle $\left(159.7^{\circ}\right)$. The surface roughness is believed to play an important role for the exceptionally large contact angle, which is substantially larger than the previously reported value for crystalline graphite $\left(98.3^{\circ}\right)$. Less than $1 \%$ of the area is in fact in contact with the water drop according to the Cassie-Baxter equation. The small $\mathrm{CH}_{2} \mathrm{I}_{2}$ contact angle close to $0^{\circ}$ is also consistent with the hydrophobicity of black carbon.

Acknowledgments. This work is partially supported by University of Incheon Research Grant in 2011.

\section{REFERENCES}

1. Bond, T. C.; et al. J. Geophys. Res.: Atmospheres 2013, $118,1-173$, and references therein.

2. Heo, J.-Y.; Cho, C.-H.; Jeon, H.-S.; Cheong, B.-S.; Cho, H.-G. Spectrochim. Acta A 2011, 83, 425-431.

3. Hendra, P. J. Spectrochim. Acta A 1995, 51, 2205-2208.

4. Cho, S.-R.; Cho H.-G. J. Korean Chem. Soc. 2013, 57, 432-438.

5. Saffaripour, M.; Kholghy, M.; Zhang, Q.; Dworkin, S. B.; Thomson, M. J. P. Combust. Inst. 2013, 34, 1057-1065.

6. (a) Young, T. Philos. Trans. R. Soc. London 1805, 95, 65. (b) Zielecka M. Polimery 2004, 49, 327-332. (c) Tadmor, R. Langmuir 2004, 20, 7659-7664.

7. Lim, H. S. KIC News 2012, 15, 11-22.

8. Wang, S.; Zhang, Y.; Abidi, N.; Cabrales, L. Langmuir 2009, 25, 11078-11081.

9. Campbell, D. J.; Andrews, M. J.; Stevenson, K. J. J. Chem. Edu. 2012, 89, 1280-1287. 